\title{
Germano Almeida, a ficcionalização do tempo da infância
}

\section{Germano Almeida, the Fictionalization of Childhood}

\author{
Lola Geraldes Xavier [lolagrafias@gmail.com] \\ 澳門理工學院 (Instituto Politécnico de Macau), China \\ Instituto Politécnico de Coimbra, Portugal \\ Centro de Literatura Portuguesa, Portugal
}

\begin{abstract}
RESUMO
Se a obra é independente do autor, o romance não se dissocia de um tempo histórico em que é escrito. Germano Almeida, escritor cabo-verdiano, assume que a sua escrita é inspirada em factos reais que posteriormente ficciona. Na obra, o escritor recupera, através das suas vivências, estórias de Cabo Verde. Centrar-nos-emos em Regresso ao paraíso, o seu romance de 2015. Aí, o acesso ao tempo da infância, decorrida na ilha da Boa Vista, dá-se através da memória. Este recuo ao passado possibilita a reconstrução histórica, ainda que ficcionada, de uma ilha, parecendo viver à margem do jugo colonialista.
\end{abstract}

\section{Palavras-Chave}

memória; tempo; infância; identidade; Cabo Verde

\begin{abstract}
If a literary work is independent from its author, the novel is not dissociated from a historical time in which it is written. Germano Almeida, Cape Verdean writer, assumes that his writing is inspired by fictionalized real facts. In his work, the writer recovers Cape Verde stories, through his experiences. We will focus on Regresso ao paraíso, his novel from 2015. Here, the childhood memory, of the island of Boa Vista, constructs the reality. This return to the past allows a historical reconstruction, although fictionalized, of an island apparently living on the edge of the colonial yoke.
\end{abstract}

\section{KeYWORDS}

memory; time; childhood; identity; Cape Verde

RECEBIDO 2017-08-26; ACEITE 2017-11-08 
Começa assim Regresso ao paraíso, do escritor cabo-verdiano Germano Almeida:

São já passados muitos anos desde que deixei de viver na Boa Vista. Porém, durante muito tempo, normalmente entre os meses de julho e setembro, arranjava maneira de lá passar alguns dias. Era um regresso ansiado e sempre festivo que me devolvia aos dias da infância, sobretudo porque guardo ainda na memória todos os sabores da minha meninice [...]. (Almeida 2015: 7)

Regresso ao paraíso não é uma autobiografia, não é uma biografia, não é o que se poderia designar, de forma rigorosa, escrita memorialista. Não o é na forma. É-o na intenção. É-o na medida em que o recurso à memória permite a construção da identidade tradicional de Cabo Verde. É-o enquanto relato de memórias e experiências vividas na infância, ainda que ficcionadas. É-o pelo recurso a processos que caracterizam a recordação. É-o na envolvência espacial e social que descreve.

O paratexto do livro, através da capa, esclarece que se trata de um romance, ficção, portanto. Mas quem conhece Germano Almeida ${ }^{1}$ e a sua obra sabe que a sua escrita é inspirada em factos reais que posteriormente ficciona. Em relação a Regresso ao paraíso, diz o autor: "Escrevo o Regresso ao paraíso de uma assentada, revendo as minhas memórias. Começo a escrever e as pessoas voltam todas. Com as vozes, os sons. São efabuladas, também.”2 A memória permite, assim, o acesso à história, no sentido em que "o dever de memória faz de cada um o historiador de si mesmo" (Nora 1993: 17).

A memória, para Tedesco (2011: 13), tem uma pluralidade de funções em correlação, não apresenta uma sequência factual e temporal, antes uma dialética temporal e dos fenómenos sociais. Nesse sentido, a memória permite a reprodução dinâmica de fenómenos culturais e sociais. Assim, as memórias de cada indivíduo são inseparáveis dos lugares em que viveu e das pessoas que habitavam esses lugares. Deste modo, as memórias individuais, através de um trabalho de antropologia da memória (Candau 2006), refletem sempre a memória coletiva de uma dada época e espaço.

No caso de Germano Almeida, o espaço é o das ilhas de Cabo Verde, que estão na génese da sua inspiração. Logo pelos títulos de algumas das suas obras podemos constatar isso: De Monte Cara vê-se o mundo (2014), referindo-se à elevação na ilha de São Vicente, em que a cidade do Mindelo se destaca como personagem; O Mar na Lajinha (2004), evocando a praia no coração do Mindelo; A família Trago (1988), crónica sobre uma família da Boa Vista, e Viagem pela história das ilhas (2003), apresentação histórica das nove ilhas habitadas de Cabo Verde.

Este espaço real, enquanto referência extralinguística, está presente em Regresso ao paraíso, através das alusões geográficas à praia de Cabral, a Sal-Rei, por exemplo, que existem efetivamente em Boa Vista.

1 Germano Almeida nasceu na ilha da Boa Vista, em Cabo Verde, em 1945. Estudou Direito na Universidade de Lisboa e exerce advocacia na ilha de São Vicente, também em Cabo Verde. Desempenhou o cargo de Procurador-Geral da República de Cabo Verde. Foi um dos cofundadores da revista literária Ponto \& Vírgula.

Os seus romances estão traduzidos em várias línguas. Relembramos apenas algumas obras que escreveu: $\mathrm{O} M e u$ Poeta (romance, 1989); O testamento do Sr. Napumoceno da Silva Araújo (romance, 1991); A morte do meu poeta (romance, 1998); As memórias de um espírito (romance, 2001); Eva (romance, 2006); Regresso ao paraíso (romance, 2016).

2 Entrevista de Germano Almeida a Mariana Pereira, Diário de Notícias, 03/2/2016, in http://www.dn.pt/artes/ interior/nao-vou-a-ilha-da-boa-vista-o-meu-paraiso-ha-quase-20-anos-nao-preciso-5011952.html 
Regresso ao paraíso é um romance sem capítulos, como se a narração fosse, de facto, ao sabor da memória, sem interrupções ou cortes paratextuais que pudessem desviar o leitor do discorrer das lembranças do passado.

Em 2006, foi publicada uma antologia do conto inédito cabo-verdiano, Tchuba na Desert, organizada por Francisco Fontes. A abrir a antologia temos acesso a três contos de Germano Almeida: "Estória para a boquinha da noite", "A água e o ritual do namoro", "O nascimento na era da civilização e progresso". Estes contos são sobretudo descritivos, estão interligados e mais se diria serem capítulos de narrativa autobiográfica sobre a infância do autor, na Boa Vista. Nove anos depois vamos encontrar essa prosa em Regresso ao paraíso: "Não tenho ideia de quando fui escrevendo esses contos. Sei que os encontrei certo dia no computador, fui relendo e achei que valia a pena publicá-los. Só há uns 2 ou 3 anos decidi transformá-los no Regresso ao Paraíso" (Almeida 2017) .

Algumas passagens adaptadas destes três contos de 2006 fazem parte, não de forma seguida, do romance publicado em 2015. O romance desenvolve outros usos e costumes da ilha da Boa Vista, sobretudo antes da chegada do progresso. Mas refere também usos e costumes tratados anteriormente como: a ida à pesca (referida sumariamente no final do romance), a ida à fonte e a relação com o namoro, o cerimonial no $7^{\circ}$ dia após o nascimento de uma criança, de modo a afastar as bruxas, e a forma de tratar as doenças - das mezinhas tradicionais caseiras aos medicamentos de farmácia.

Faça-se, a título de exemplo, o cotejar de um excerto de um conto publicado em Tchuba na desert e de um excerto deste romance:

\section{Conto "A água e o ritual do namoro", Tchuba na desert:}

Normalmente a ida à fonte era em alentado grupo de mulheres, quase sempre raparigas da mesma idade. Já a prever a hipótese de acontecimentos imprevistos, elas evitavam a presença de pessoas mais velhas a exigir respeito e recato no comportamento. Porque acontecia com muita frequência o rapaz estar à espera num ponto estratégico, normalmente escondido numa moita de tarafe, de longe acompanhando as moças no regresso da fonte em alegre parladeira. E de repente, zás!, ele planta-se em frente da requestada. (Almeida 2006: 31-32)

\section{Regresso ao Paraíso:}

Normalmente a ida à fonte fazia-se em alentado grupo de mulheres, quase sempre alegres raparigas da mesma idade caminhando no meio de felizes algazarras. Já prevendo a hipótese de acontecimentos imprevistos, como por exemplo o aparecimento repentino de um pré-namorado, propositadamente evitavam entre elas a presença de pessoas de mais idade, a exigir mais respeito e recato no comportamento, afinal das contas o meio é pequeno e todos se conhecem e se tratam como parentes. Porque acontecia com muita frequência o aspirante à condição de namorado estar à espera num ponto estratégico, normalmente escondido numa moita de tarafe, acompanhando à distância as moças que regressavam da fonte cantando em coro ou simplesmente contando estórias. E de repente ele salta para o caminho e planta-se em frente da requestada. (Almeida 2015: 120; sublinhados nossos)

\footnotetext{
3 Excerto de entrevista que fizemos por escrito a Germano Almeida, em 25/10/2016 (por e-mail).
} 
Constatamos que este excerto de Regresso ao Paraíso é mais longo, sendo desenvolvido a partir do conto "A água e o ritual do namoro". Colocou-se em itálico as partes que são introduzidas no romance por comparação com o conto.

O narrador do romance parece ter a preocupação de dar ao leitor o máximo de informação sobre este episódio bucólico, que nos faz recuar ao cenário das cantigas de amigo e da importância da tradição oral. O "rapaz" do conto, mencionado apenas uma vez, é neste excerto do romance um "pré-namorado" e o "aspirante à condição de namorado", destacando-se, aqui, a importância do papel desta figura masculina.

A própria natureza genológica do romance, mais extenso, permite também que haja o desenvolvimento de descrições e narrações a partir destes contos. Por outro lado, passam-se, pelo menos, nove anos entre a escrita do conto e a do romance, o que permitiu ao autor burilar a sua escrita. O excerto do romance apela ao sentido da audição, insistindo em adjetivos do campo semântico da alegria, o que se coaduna com a idade das raparigas e a liberdade que sentem nessa ida à fonte.

Não há, porém, nos contos as personagens principais que encontraremos mais tarde no romance. Aqueles parecem apenas terem como objetivo fazer o relato memorialista do modo de vida na Boa Vista.

O romance, enquanto código que funciona como um filtro da realidade, da sociedade e do Homem, no plano temático e formal, adequa-se às evocações que o narrador deste texto efetua. Trata-se de um narrador de primeira pessoa que regressa à sua infância, antes de ter 12 anos, numa altura em que se andava descalço e que, por isso, acontecimentos como o do surgimento das sandálias de plástico ganham relevo pela evocação. É um narrador-personagem descendente de uma família branca que se preocupa em "melhorar a raça da família" (Almeida 2015: 97) e não vê com bons olhos os casamentos com negros. Esta família de classe média obtém os rendimentos da exploração de uma mercearia onde vivia, no Bom Sossego (cf. Almeida 2015: 249), onde o autor empírico nasceu e ainda tem casa.

O narrador posiciona-se como personagem que observa. Apresenta-se como um alter ego do autor. É um narrador que passou a infância em Boa Vista, como o autor, que também gosta de escrever: "ocorreu [me] escrever um ensaio que intitulei de "O último bruxo da ilha". Nesse ensaio eu pretendia primeiro fazer a estória geral da bruxaria nas ilhas, indo portanto aos seus tempos mais recuados" (Almeida 2015: 137). É um narrador que parece recolher testemunhos de familiares, como da tia Dina, para usar "unicamente para efeitos literários" (Almeida 2015: 40).

O regresso ao paraíso é o tempo idílico da infância, da prevalência do mundo tradicional sobre o moderno, da construção da percepção da realidade, do contato com a natureza. Esse recuo faz-se através da memória de um narrador, qual contador de estórias, que se se servisse de outros contadores. A forma como o romance termina, com a ênfase no "contar estórias" (últimas palavras da obra), remete-nos para a importância da oralidade, quer no mundo tradicional a que o narrador recua, numa longa analepse, quer no presente em que conclui o romance e observa a ilha, objeto da sua evocação do passado:

A noite já caía, mas o céu estava parado e limpo, o mar era um imenso lençol azul apenas perturbado pela breve ondulação do bote, era bom estar assim vogando devagarinho e sem destino vendo ao fundo a branca quietude da ilha, e todos estivemos de acordo que ainda era 
cedo, tínhamos muito tempo, de certeza absoluta que em alguma hora um reboque haveria de aparecer. E sentados na borda do bote, as mãos brincando na água, começámos à vez a contar histórias. (Almeida 2015: 287)

Os sons vibrantes neste final de romance atribuem ritmo e transmitem a "quietude da ilha" evocada. O "contar" é portanto o verbo que comanda a narrativa. E, para isso, personagens como Nho Quirino, do seu livro A ilha fantástica, velho contador de estórias, estão presentes também neste romance para "contar as suas infindáveis estórias" (Almeida 2015: 147).

A participação de outros contadores de estórias, ao luar, muitas vezes contadores de ocasião, povoava um universo de heróis omnipotentes contra as forças do mal, bruxas, almas penadas, dragões terríveis: "Mas mesmo para nós, meninos, a coisa seria caricata, não fosse o ambiente de terror que os contadores conseguiam criar à volta das narrativas orais, mantendo-nos em suspenso, à espera de ver surgir a qualquer momento e de qualquer canto o monstro adversário [...]" (Almeida 2015: 102).

É, pois, um narrador que vai contando as estórias ao sabor da memória: "Lembro-me ainda de que aqueles tempos pavorosos só os homens muito destemidos se atreviam, depois da meianoite, a abandonar a segurança das quatro paredes das suas casas e enfrentar os perigos das ruas temerosamente desertas e hostis" (Almeida 2015: 75).

Germano Almeida usa a literatura enquanto “instituição de índole sociocultural” (Silva 1997: 39), e, nesse sentido, não é de surpreender que se sirva da ficção para descrever a sociedade e os usos e costumes de uma época. Deste modo, a contaminação da tradição oral cabo-verdiana no romance é perceptível através dos seus próprios ingredientes: estórias de amor, casamentos por interesse, vitória do bem sobre o mal. Trata-se de uma comunidade em que as bruxas convivem com os elementos religiosos da fé cristã, em que as pessoas saltam de uns elementos para os outros, sem perturbações ou interferências, com naturalidade.

Este universo mítico do passado é derrubado pela chegada da luz eléctrica e contrasta com o presente, como esclarece ironicamente o narrador: "Hoje em dia descobrir um bruxo numa qualquer das aldeias das ilhas é um verdadeiro achado, quase um acontecimento digno de se chamar a imprensa a noticiar o facto" (Almeida 2015: 137).

O narrador rememora a mudança da ilha da ruralidade para o desenvolvimento. A narrativa ajuda a entender a passagem da ilha da Boa Vista do tradicional para o moderno e as marcas de cada uma dessas épocas. Uma pergunta se coloca, então: o que resta desse passado? Como escreve Germano Almeida no conto "Estória para a boquinha da noite": "Bem, tudo isto já é estória, da Boa Vista da minha infância pouco mais resta para além do prazer de usar o tempo. É uma noção de prazo em que o hoje e o amanhã, o agora e o mais daqui a bocado continuamse confundindo e significando a mesmíssima coisa" (Almeida 2006: 28).

Esta ideia é retomada em Regresso ao paraíso:

Bem, tudo isso já é história. A pulguinha pressupõe chuva e verduras, e isso tudo acabou. Dizemme que mesmo em São Nicolau sua terra de origem já não é senão uma lembrança. De modo que da Boavista da minha infância pouco mais já resta que o prazer de usar tempo. É uma noção de tempo em que o hoje e o amanhã, o agora e o mais daqui um bocado, continuam significando a mesmíssima coisa. (Almeida 2015: 283; negritos do autor) 
Nota-se, aqui, no romance, mais uma vez, a adaptação, por extensão, de uma parte do conto publicado em 2006. O narrador enfatiza (até pelo uso do negrito) a noção cultural de tempo africano, em que vários tempos confluem no presente, o que contrasta com a relação que se vai criando ao longo do romance. Neste estabelece-se um dialogismo entre passado e presente, entre a ruralidade e o progresso. $\mathrm{O}$ tempo não é, pois, apresentado como homogéneo, mas antes um tempo "saturado de «agoras»" (Benjamin 1994: 229).

O narrador parece oscilar entre as vantagens da modernização e os efeitos nefastos: "destruidora ânsia de modernização" (Almeida 2015: 12), como se o progresso fosse o responsável por não encontrar já na ilha, enquanto adulto, o paraíso que a memória do passado lhe dita. Nesse sentido, é descrita a vida ligada à ruralidade: no campo, na horta, no curral, a guardar as cabras.

Está-se em presença de uma atitude hermenêutica de decifração de um universo passado diferente do presente em que o narrador escreve. Trata-se de um passado de ruas de terra batida, casas caiadas, sem comodidades técnicas, mas em que há um forte sentido de comunidade. Não há telefone, frigorífico, televisão, quase não há automóveis. A energia elétrica e as suas consequências, os transportes e vias de comunicação foram ingredientes positivos, mas o progresso também trouxe inconvenientes. Transformou as relações entre as pessoas, alterou a noção de comunidade, a forma de as pessoas se relacionarem e dependerem umas das outras, a forma de flirtar. Perdeu-se "imensas coisas e imensas lendas e fantasias que enriqueciam o nosso imaginário coletivo" (Almeida 2015: 74). Porém, essa constatação faz-se com resignação: "Bem, hoje em dia já não é assim” (Almeida 2015: 55); “Bem, hoje tudo isso já pertence à história. Hoje os meninos nascem nos hospitais, assistidos não pelas empíricas parteiras tradicionais mas por especializadas enfermeiras de batas brancas e luvas cuidadosamente desinfetadas" (Almeida 2015: 141); “Bem, tudo isso já é passado” (Almeida 2015: 151); “Bem, tudo isso já faz parte da nossa história" (Almeida 2015: 153). A forma como o narrador coloca em contraste o passado com o presente, como um desabafo de síntese da situação, mostra a sua resignação. Essa resignação, acentuada pelo uso do bordão linguístico "bem", que aproxima a narração da oralidade, advém da constatação de que a evolução é inelutável: "Aliás, a ilha toda mudou muito nos últimos trinta/quarenta anos" (Almeida 2015: 52); "E assim a pouco e pouco acabamos também entrando na civilização e no progresso, com a ilha a averbar conquistas até há bem pouco tempo inimagináveis" (Almeida 2015: 154). O narrador constata a inevitabilidade do progresso e as suas vantagens, não deixando de olhar com alguma nostalgia para o passado, mais original e natural.

O início dessas mudanças parecem “hoje já distantes” (Almeida 2015: 60) e vieram trazer o "caminho das modernidades em que agora nos comprazemos e deliciamos" (Almeida 2015: 60). Este recuo ao passado para mostrar o impacto da chegada do progresso às ilhas é frequente na obra de Germano Almeida. Veja-se, por exemplo, o livro que ganhou notoriedade O testamento do Sr. Napumoceno da Silva Araújo, e o gosto da personagem principal do romance em acompanhar a evolução da técnica, tendo sido o primeiro habitante da ilha a trazer dos EUA várias novidades desconhecidas nas ilhas (cf. Almeida 2007: 46).

Em Regresso ao paraíso, as personagens são apenas sumariamente descritas, interessa mais ao narrador contar a ambiência ou estórias que permitam perceber como se vivia na época. A descrição da ilha mistura-se com lembranças do quotidiano e tipos humanos que povoaram 
a sua infância. Sendo uma narrativa que contempla o coletivo, a narração da vida das pessoas na ilha, pode dizer-se que a personagem principal é a própria ilha.

Neste livro é como se se erguesse uma bandeira da luta contra o esquecimento sobre o passado da ilha e os seus hábitos e costumes, tentando salvar-se do esquecimento tradições e usos do passado na ilha da Boa Vista.

De facto, são vários os costumes de Boa Vista rememorados ao longo do romance, como os que se prendem com a alimentação. As referências repetidas à cachupa, aos vários usos do cachalote, ao cuscuz de milho ou de mandioca, aos bolos secos, etc., bem como ao ritual das refeições, ilustram formas de sociabilidade. Desse modo, descreve-se a alimentação, e, através dela, o leitor tem acesso à aspetos da vida em sociedade.

Refere-se também os tipos de jogos das crianças (futebol, corrida a pau, tacada, ringue, brincar à roda) e os hábitos de higiene. São descritos costumes ligados à cerimónia de casamento, ao tipo de organização familiar, de família alargada: "esta casa que continua cheia de gente como quando a conheci há quarenta anos. Já reparaste que aqui nem se sabe quem é filho de quem se não se perguntar, de tal forma vivem misturados?" (Almeida 2015: 165).

Outros costumes, como a forma de namorar e flirtar, são destacados. No geral, as personagens ou figurantes, quer homens quer mulheres, são namoradeiros. Os homens são apresentados de uma forma geral mais negativa do que as mulheres. Dina, a meia-irmã do narrador, regressada da América, descreve de forma nada eufórica os homens não só da ilha, como do arquipélago: "esse é um mal de todos os homens de Cabo Verde, não respeitam as mulheres" (Almeida 2015: 167). Esta imagem é corroborada por outras personagens como nho Marqueza, ao falar de Possidónio a Dina: "Como ele nunca trazia ninguém para casa, nenhuma mulher, e como também praticamente não saía, comecei a ficar intrigada, não pareceria coisa de cabo-verdiano" (Almeida 2015: 172). O narrador dá-nos, pois, acesso à caracterização do modus vivendi dos cabo-verdianos, não apenas pela descrição de situações, mas também através dos testemunhos das próprias personagens. Não poderia deixar de estar, igualmente, presente a alusão ou narração de episódios sobre a emigração de alguns habitantes de Boa Vista para os Estados Unidos da América ou para a Holanda.

Ao longo da obra, descreve-se a forma caseira de resolver os problemas de saúde com remédios tradicionais, demasiado surpreendente e incrível para os dias de hoje, o que coloca em oposição a crendice com a ciência. A explicação das coisas empíricas é feita através do recurso ao desconhecido, aos espíritos e à religião. Assim, do recurso às mezinhas caseiras passou-se a recorrer à medicina ocidental: "Bem, tudo isso já é passado. Agora pouca gente já acredita em espíritos ou forças fora da terra, e por isso para qualquer coisinha logo se corre para a farmácia, é aspirina, é paracetamol [...]" (Almeida 2015: 151).

O tempo tem vindo a deturpar as tradições iniciais da ilha, passando a interpretar-se tradições de uma forma que já nada têm a ver com o original, como a apresentação do recém-nascido aos amigos, "a noite de sete", que, da tradição associada a crendices, passou a um evento social, completamente afastado do costume original, levando o narrador a desabafar: "Meu Deus, pensei, a que degenerações nos sujeitamos para mantermos os costumes da terra!" (Almeida 2015: 151). Neste sentido, o narrador parece experimentar a responsabilidade de escrever a autenticidade dos seus costumes para que se registe para a posteridade a verdadeira origem de uma identidade nacional. 
Claro que pensar em memória e história exige centrar-se no sujeito que evoca e escreve e, assim, o locus original é rememorado pelo narrador numa perspetiva social. Se o título do livro nos remete para uma imagem paradisíaca de um lugar ideal, utópico, da infância, a verdade é que nesse paraíso também há acontecimentos trágicos, mortes, doenças, relacionamentos amorosos frustrados, filhos fora do casamento, etc. Porém, a comunidade é entendida de forma alargada, as famílias são grandes e, por exemplo, acolhem filhos fora do casamento, sem pruridos.

Essas estórias trazem alguns contributos para a História, se entendermos História como forma de pensar o passado. Para Walter Benjamim (1994), a História é um processo inacabado de construção e reconstrução e, nesse sentido, a memória desempenha um papel importante.

Jacques Leenhardt (1996) defende, também, que o discurso literário auxilia a História, no plano do imaginário e ficcional, pois permite o acesso ao universo passado. Se entendermos a ficcionalidade como um conjunto de regras que regulam as relações entre o mundo do texto e o mundo empírico, o texto literário constrói um mundo fictício através do qual modeliza o mundo empírico, representando-o e instituindo uma referencialidade mediatizada. Nesse sentido, esta narrativa de Germano Almeida estabelece uma relação com a realidade, com a história. Essa relação dá-se na evocação dos locais, na localização espacial, nas referências à economia da ilha, como a pesca e a Fábrica Ultra, fábrica de Conservas e Embalagem de atum, do tempo dos portugueses.

Segundo Aguiar e Silva (1997: 625), “o texto é sempre, sob modalidades várias, um intercâmbio discursivo, uma tessitura polifónica na qual confluem, se entrecruzam, se metamorfoseiam, se corroboram ou se contestam outros textos, outras vozes e outras consciências." Há alguns sinais desse intercâmbio discursivo em Regresso ao paraíso através de intertextualidade. Veja-se a referência e citação de Francisco Travassos Valdez (1861), árbitro da comissão para a abolição da escravatura, sobre a escassez de água na povoação Sal-Rei e a possibilidade de proceder à canalização da água a partir da ribeira da Boa Esperança. Canalização que se fez por volta de 1960, sob a direção de um português (Balão). Esta intertextualidade com documentos históricos (cf. Germano 2015: 130), os pormenores de nomes e locais remetem-nos para a preocupação de registo histórico como forma de a narrativa reconstruir a identidade das gentes da ilha da Boa Vista.

Há, pois, uma insistência em localizar a narração "naquele tempo", um tempo em que a caraterização política não é muito explorada. Apenas numa circunstância, uma personagem (marido de Dina) faz referência ao partido da União Nacional, a Salazar e à perseguição feita a quem não era a favor do regime. No romance há ainda outras alusões ao mundo extraliterário, como a menção ao banco BNU e a referência ao uso obrigatório do Português no Seminário. Com este último facto, mostra-se que a Igreja estava ao serviço da difusão da ideologia do regime e da consolidação e unificação através da língua portuguesa, proibindose o uso do crioulo.

Percebe-se que se trata de um período em que os portugueses eram deportados para as colónias e que, apesar de deportados de Portugal, conseguiam entrar nas melhores famílias da terra (pelo casamento). Também os cargos de chefia e direção eram exercidos por portugueses "mandados de Lisboa" (Almeida 2015: 65).

É referida a visita de Craveiro Lopes, presidente da República Portuguesa, entre 1951 e 1958, às ilhas, apresentado como 'o presidente' - nota-se a união com Portugal, sem discussões de in- 
dependência ou sentimento visível de colonialismo. Este facto permite-nos situar parte da ação em 1955, ano em que Craveiro Lopes visitou a Guiné-Bissau e Cabo Verde.

A condição política e ideológica da época não é, pois, mais do que esboçada no romance. Mais do que qualquer enredo, Regresso ao paraíso dedica-se sobretudo a descrever a vivência na ilha da Boa Vista, num período colonialista. Um período que parecia não pesar nos habitantes que conduziam o seu dia-a-dia sem qualquer tipo de preocupação política ou ideológica. A infância não se compadece com essas preocupações e a ilha da Boa Vista parecia viver alheia a situações políticas.

O realismo consegue-se neste romance não só pelas referências extraliterárias, mas também pela linguagem coloquial, pelo uso de expressões populares, por vezes, mesmo, escatológicas, usadas pelas personagens, em discurso indireto livre. Veja-se o exemplo seguinte, sobre o diálogo (em forma de discurso indireto livre) entre Nho Liminha e Dina, no barco que a levaria à América:

Lá para o décimo quinto dia de viagem Dina disse que queria levantar-se e tomar um banho. Muito bem, disse Nho Liminha, mas primeiro levantas-te e ficas aqui sentada um bocado na minha cadeira de lona, a ver como o teu corpo reage, depois de tantos dias deitada é um perigo levantar-se da cama e logo começar andar, podes até arrebentar uma veia, e aí adeus Dina! Dina riu-se, Não se perdia grande coisa, disse. Não digas isso, repreendeu-a Nho Liminha, és jovem, és ainda uma criança, tens uma longa vida à tua frente, tens montes de coisas boas e receber da vida, não te deixes desanimar porque por cada porta que Deus fecha, ele mesmo abre mil, vais ver, ainda havemos de falar, és uma moça bonita que vai dar cartas na América, vais ver. (Almeida 2015: 161-162)

O narrador utiliza, nesta passagem, marcas da oralidade, características da linguagem popular, quer através de lexemas (“arrebentar”), quer através de expressões (“dar cartas”) ou de ditados populares ("por cada porta que Deus fecha, ele abre mil”). Nota-se, ainda, o uso de repetições anafóricas, que imprimem ritmo ao discurso ("vais ver”), do diálogo, sem marcas gráficas do discurso direto, combinado com discurso indireto livre. Existe, assim, uma pluralidade de vozes, uma polifonia narrativa que mistura a voz do narrador com a de outras personagens, através do discurso indireto livre, uma herança da oratura, ou de discurso direto incorporado na narração.

Ao longo do romance, assiste-se ainda ao uso de bordões linguísticos ("Bem [...]" - Almeida 2015: 178, 189); lugares comuns ("o mundo é pequeno" - Almeida 2015: 178); aforismos (“o homem põe e Deus dispõe” - Almeida 2015:174) e provérbios ("água mole em pedra dura tanto bate até que fura” - Almeida 2015: 189). O código linguístico serve, assim, de elemento de captação estilística, integrando a mimetização da oralidade. O real é, pois, plasmado pelos traços ideoletais e socioletais reproduzidos ao longo do romance.

Concluindo, Regresso ao paraíso apresenta-nos uma escrita social que descreve acontecimentos do quotidiano. A escrita decorre do apelo à memória, ainda que ficcionalizada. Como se se tratasse de um memorialismo-ficção, em que o narrador escreve as suas memórias de infância. Como se a memória transmitisse, sobretudo, a ambiência que permite ao narrador escrever: "Mas no geral os nossos dias eram alegres e felizes" (Almeida 2015: 9). A cultura e as 
representações chegam-nos, por conseguinte, através da memória. A memória recupera, pela evocação, representações culturais, sensibilidades, o imaginário da infância, o viver saudável e feliz.

O romance apresenta uma época de que se foram apagando vestígios, mas que contribuíu para a identidade da ilha. Ajuda-se, assim, a construir uma identidade nacional.

Apesar de todas estas marcas, não podemos, todavia, tomar as obras memorialistas como descrições fiéis da realidade que procuramos estudar. Também não podemos considerar literalmente as recordações do narrador-personagem de Regresso ao paraíso totalmente fidedignas até porque são produzidas dentro do universo de ficção assumida pelo autor do texto.

A obra de Germano Almeida é o lugar teórico-prático onde a história, as tradições e valores se estruturam como cultura literária. Trata-se de narrativas que fazem a síntese entre textos e tempos anteriores. Nesse sentido, em Regresso ao paraíso reescreve-se a história, recuperando rituais, crenças e mitos da ilha da Boa Vista. A literatura cumpre, assim, também, o papel de memória, revelando uma sociedade que permite reconstruir os factos passados.

O memorialista procura trazer detalhes e descrições da realidade que viu e viveu, passando a ideia de alguém que foi testemunha viva de um período histórico. O autor, através do seu narrador-personagem, parece mostrar que "o passado e a memória não são história, mas seus objetos e um nível elementar de elaboração histórica” (Le Goff 1990: 49).

Germano Almeida responde assim à relação de Regresso ao paraíso com a realidade histórica: "Bem, nunca pretendi qualquer papel particular para as minhas estórias, apenas contá-las por prazer. Misturar factos com ficção é divertido e gosto de o fazer.” ${ }^{4}$

Numa palavra, tendo em consideração a índole ficcional desta obra e o caráter seletivo da memória, esta narrativa não tem que ser encarada como um reflexo do real, mas como uma fonte que tem de ser questionada e reelaborada através de trabalho histórico. Trata-se, pois, de uma obra entre a fronteira do romance e do memorialismo, de escrita ficcional que parte de memórias da infância.

\section{Referências bibliográficas}

Almeida, G. (2006). Estória para a boquinha da noite; A água e o ritual do namoro; O nascimento na era da civilização e progresso. In F. Fontes (Org.), Tchuba na desert - antologia do conto inédito caboverdiano (pp. 25-42) Coimbra: Saúde em Português.

. (2007). O testamento do Sr. Napumoceno da Silva Araújo. Lisboa: Caminho.

. (2015). Regresso ao paraíso. Lisboa: Caminho.

Benjamin, W. (1994). Magia e Técnica, Arte e Política: Ensaios sobre Literatura e História da Cultura. São Paulo: Brasiliense.

Candau, J. (2012). Memória e identidade. São Paulo: Contexto.

Le Goff, J. (1990). História e Memória. São Paulo: Unicamp.

Leenhrdt, J. (1996). La littérature: une entrée dans l'histoire. Littérature/Histoire, regards croisés, 20, 15-25.

4 Excerto da entrevista que fizemos ao escritor a propósito deste livro (25/10/2016 - por e-mail). 
Leite, A. M. (1988). Oralidades e escritas nas literaturas africanas. Lisboa: Edições Colibfonte.

Nora, P. (1993). Entre Memória e História: A problemática dos lugares. Projeto História, 10, 7-28.

Pereira, M. (2016). Não vou à ilha da Boa Vista, o meu paraíso, há quase 20 anos, não preciso. $D N$ (03/fevereiro/2016). <http://www.dn.pt/artes/interior/nao-vou-a-ilha-da-boa-vista-o-meu-paraiso-ha-quase-20anos-nao-preciso-5011952.html>

Silva, V. M. A. E (1997). Teoria da Literatura. Coimbra: Livraria Almedina.

Tedesco, J. C. (2011). Passado e presente em interfaces: introdução a uma análise sócio-histórica da memória. Passo Fundo: EDUPF. 
